\title{
Transcription of a yeast U6 snRNA gene requires a polymerase III promoter element in a novel position
}

\author{
David A. Brow ${ }^{1,2}$ and Christine Guthrie \\ Department of Biochemistry and Biophysics, University of California, San Francisco, California 94143-0448 USA
}

\begin{abstract}
Vertebrate genes coding for U6 small nuclear RNA are transcribed by RNA polymerase III (pol III), using only upstream promoter elements rather than the $A$ and B block internal control regions typical of most pol III transcription units. We show that expression of the U6 gene from the yeast Saccharomyces cerevisiae has two unexpected features: it requires a B block promoter element, and this element is located in a novel position, 120 bp downstream of the coding region. In tRNA genes, the $B$ block is the primary binding site for transcription factor (TF) IIIC, whose function is to promote the subsequent binding of TFIIIB. Both factors are thus implicated in yeast $\mathrm{U} 6$ gene transcription. We present a model of the U6 transcription complex based on the structure of yeast and vertebrate U6 promoters.
\end{abstract}

[Key Words: U6; snRNA; pol III transcription; B block; TFIIIC]

Received March 19, 1990; revised version accepted May 14, 1990.

U6 small nuclear RNA is one of five snRNAs essential for spliceosome-mediated processing of premessenger RNA (for review, see Guthrie and Patterson 1988). It is the only spliceosomal snRNA synthesized by RNA polymerase III (pol III; Kunkel et al. 1986; Reddy et al. 1987); the others are synthesized by pol II (see Dahlberg and Lund 1988). Genes transcribed by pol III, including transfer RNA and 5S ribosomal RNA genes, characteristically have predominantly intragenic promoters (for review, see Geiduschek and Tocchini-Valentini 1988). For example, tRNA genes contain two conserved intragenic promoter elements, the A and B blocks. The A block is nearest the $5^{\prime}$ end of the gene and specifies the point of transcription initiation, whereas the B block is $30-90 \mathrm{bp}$ farther downstream and is the primary binding site of the pol III transcription factor TFIIIC. Binding of TFIIIC is obligatory for binding of another factor, TFIIIB, resulting in formation of a stable transcription complex recognized by pol III. TFIIIB and TFIIIC are presumed to be generally required for pol III transcription.

It was therefore surprising when transcription by pol III of a human 7SK gene and a mouse U6 snRNA gene was shown to be dependent only on sequences upstream of the initiation site (Murphy et al. 1987; Das et al. 1988). Three conserved upstream elements important for vertebrate $\mathrm{U} 6$ gene promoter function have been identified: the distal sequence element (DSE; Bark et al. 1987; Carbon et al. 1987; Das et al. 1988; Kunkel and

${ }^{1}$ Corresponding author.

${ }^{2}$ Current address: Department of Physiological Chemistry, University of Wisconsin at Madison, Madison, Wisconsin 53706 USA.
Pederson 1988), the proximal sequence element (PSE; Carbon et al. 1987; Das et al. 1988; Kunkel and Pederson 1988; Mattaj et al. 1988; Lobo and Hernandez 1989), and a T/A-rich element similar in sequence and location to the pol II TATA box (Mattaj et al. 1988; Lobo and Hernandez 1989). The DSE and PSE have been shown to be functionally interchangeable with similar sequences upstream of the gene coding for U2 snRNA, which is synthesized by pol II (Bark et al. 1987; Kunkel and Pederson 1988; Mattaj et al. 1988).

Remarkably, it is the TATA-like sequence $29-31$ bp upstream of the U6 snRNA start site that directs pol III to the U6 gene (Mattaj et al. 1988; Lobo and Hernandez 1989|. A similar requirement for a TATA-like sequence $\sim 30$ bp upstream of a pol III start site has been seen for the human 7SK RNA (Murphy et al. 1987) and c-myc genes (Bentley et al. 1989). Although the authors of these studies concluded that the TATA-like sequence is a binding site for a specific factor that directs pol III to the promoter, a candidate for this factor has not yet been proposed. This leaves open the question of how a sequence element best known as a binding site for a pol II transcription factor, TFIID (Sawadogo and Roeder 1985), promotes recognition of the U6 gene by pol III.

We isolated previously the U6 sRNA gene (SNR6) from the yeast Saccharomyces cerevisiae and found that it is transcribed in a homologous cell-free pol III transcription system (Brow and Guthrie 1988). Here, we report the results of a gross mutational analysis of the SNR6 promoter. Surprisingly, expression of the SNR6 absolutely requires a B block promoter element, situated in a novel position: $120 \mathrm{bp}$ downstream of the coding region. The ability of yeast U6 gene deletion constructs 
with intact B blocks, but not those with disrupted B blocks, to compete with 5S rDNA for a limiting transcription factor strongly suggests that the downstream $B$ block binds TFIIIC in vitro. In tRNA genes, TFIIIC also contacts the A block promoter element; we find a match to the A block consensus sequence at the appropriate position in the yeast U6 coding region. Because the function of TFIIIC in tRNA gene transcription is to promote binding of TFIIIB (Kassavetis et al. 1990), both factors are thus implicated in yeast U6 gene transcription. In light of recent evidence that TFIIIB binds to a region centered 20-30 bp upstream of tRNA and 5S rRNA genes (Braun et al. 1989; Kassavetis et al. 1989), we propose that TFIIIB binds the U6 gene TATA-like element and directs recognition of the U6 gene by pol III.

\section{Results}

\section{DNA sequence flanking the yeast U6 SNR6 gene}

The isolation and initial characterization of the U6 snRNA gene from the yeast $S$. cerevisiae is described in Brow and Guthrie (1988). At that time, the presence of a TATA-like sequence at position -30 and a sequence identical to the $3^{\prime}$-half of the human U6 gene PSE at position -60 were noted. For mouse and human U6 genes, $<80$ bp of $5^{\prime}$-flanking DNA (encompassing both of these elements) are necessary and sufficient to promote in vitro transcription (Das et al. 1988; Kunkel and Pederson 1988). In vivo, the DSE, located 220 bp upstream of the start site, is required additionally for efficient expression of the mammalian genes (Bark et al. 1987; Das et al. 1988; Kunkel and Pederson 1988). A preliminary deletion analysis of SNR6 revealed that a subclone containing $300 \mathrm{bp}$ of $5^{\prime}$-flanking and $30 \mathrm{bp}$ of $3^{\prime}$-flanking DNA $(-303 /+145)$ was not expressed in vivo or transcribed in vitro (data not shown). We therefore undertook a more detailed deletion analysis to locate the essential promoter element missing from this subclone but present in a larger, active subclone $(-539)+629$, see Fig. 1).

As a first step in this analysis, we sequenced more of the $5^{\prime}$ - and 3 '-flanking DNA. The sequence shown in Figure 2a represents the entirety of SNR6 upstream DNA present in our original genomic clone, and about $500 \mathrm{bp}$ of downstream DNA. The additional 5' sequence data revealed a solo delta element upstream of the conserved TATA-like and PSE-like sequences, spanning base pairs -425 to -91 (Fig. 2a). Delta elements are the long terminal repeats of the Ty retrotransposon (Cameron et al. 1979) and are responsible for both the initiation of Ty transcription by pol II and the polyadenylation of the transcript (Elder et al. 1983). Solo and Tyassociated delta elements are often located immediately upstream of tRNA genes (Gafner et al. 1983), and one has also been found upstream of a 5S rRNA gene (Piper et al. 1984); this association is presumably the result of preferential transposition of Ty to these sites, frequently followed by excision of the transposon via homologous recombination between the two delta elements. The discovery of a solo delta upstream of the U6 gene reinforces the notion that preferential integration of the Ty transposon is a general property of pol III transcription units.

Figure $2 \mathrm{~b}$ shows an alignment of the Ty-associated delta $A D H 2-6^{c} L$ and the $S N R 6$ solo delta, which are $78 \%$ identical. The delta TATA box, transcription initiation site, and polyadenylation site are all well conserved, whereas the upstream activating sequence (UAS) is more degenerate. The SNR6 delta is oriented such that, if active, it would be transcribed in the direction away from the U6 gene. Although Ty-linked delta elements similarly positioned upstream of pol II transcription units can greatly increase their expression (for review, see Williamson 1983), this is not true of solo delta elements, which lack a downstream enhancer-like sequence. Thus, the SNR6 solo delta is not necessarily expected to influence synthesis of U6 snRNA.

Another surprising finding came from the 3 '-flanking DNA sequence analysis: 120 bp downstream of the U6 snRNA-coding region lies an excellent match to the pol III B block promoter element consensus (Fig. 2a,c). The seven most highly conserved nucleotides of the 11-base consensus (Galli et al. 1981) are present. The B block is the primary binding site for TFIIIC and is required for transcription of tRNA genes and other (but not all) pol III transcription units. Although no functional B block has ever been found to lie outside of the coding region with which it is associated, our preliminary analysis suggested this downstream B block might be required for yeast U6 snRNA synthesis.

\section{In vitro transcription of SNR6 deletion constructs}

To determine the sequences required for U6 snRNA synthesis in S. cerevisiae, 5' and ' $3^{\prime}$ deletions of SNR6 were constructed. The transcriptional activity of these deletion constructs was tested in both an in vitro and an in vivo assay system. The in vitro assay used a whole-cell extract preparation active in tRNA and 5S rRNA gene transcription (Klekamp and Weil 1982). As reported previously (Brow and Guthrie 1988), the full-length subclone of SNR6 directs synthesis of U6 snRNA in this cell-free system (see Fig. 3, lane 2). Identification of the transcript is based on its size (112-115 nucleotides), its hybrid selection by a small SNR6 subclone $(-120 /$ +125 ; data not shown), and changes in its length when internally deleted SNR6 templates are used (see below). A set of four transcripts 200-300 nucleotides in length is also produced; the nature of these transcripts is discussed below. Synthesis of all the transcripts is insensitive to $1 \mathrm{mg} / \mathrm{ml} \alpha$-amanitin (data not shown), which, given the drug sensitivity of the yeast polymerases (Schultz and Hall 1976; Valenzuela et al. 1976), suggests they are products of pol III. Furthermore, when transcription is carried out in the presence of low levels of tagetitoxin, a specific inhibitor of pol III (Steinberg et al. 1990|, the yield of all transcripts is significantly reduced (T. Steinberg and R. Burgess, pers. comm.).

Figure 1 shows the structure of the $5^{\prime}$ - and $3^{\prime}$-deletion constructs and summarizes their activity in vitro. The supporting data are presented in Figure 3a. Six different 


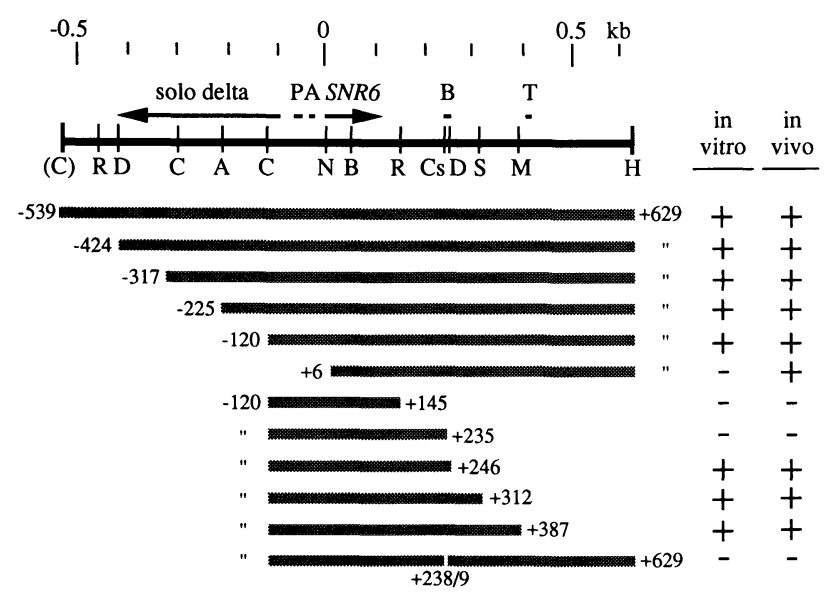

Figure 1. Structure and activity of SNR6 deletion constructs. The black bar represents $1168 \mathrm{bp}$ of $S$. cerevisiae genomic DNA. Only relevant restriction sites are shown: (A), AluI; (B) $B c l I ;$ (C) ClaI (bracketed site is dam methylated); (Cs) Csp45I; (D) DdeI; (H) HpaI; (M) MseI; (N) NruI; (R) RsaI; (S) ScaI. The position of the following sequence elements is indicated (arrows indicate direction of transcription): (solo delta) lone long terminal repeat of Ty retrotransposon; (P) PSE-like sequence; (A) A/T-rich TATA-like sequence; (SNR6) U6 snRNA gene; (B) B block consensus match; (T) downstream oligo $T$ stretch. The grey bars represent yeast DNA present in the various deletion constructs. A plus sign indicates that in vitro transcription from this template was easily detected or that strains containing only this SNR6 allele are viable. A minus sign indicates that transcription was not detected, or strains were inviable (see Fig. 3).

5 ' ends were tested. End points from -539 to -120 are all approximately equally active in vitro (Fig. 3a, lanes $2-61$, indicating that sequences within the solo delta are not important for in vitro transcription. The +6 construct, which substitutes the entire $5^{\prime}$ flank as well as 5 bp of coding DNA with vector DNA, is completely inactive (Fig. 3, lane 7). This is not surprising as it lacks the region analogous to that known to be essential for in vitro synthesis of mammalian U6 snRNA, containing the conserved TATA-like and $3^{\prime}$-PSE-like sequences.

The activity of the $5^{\prime}$-deletion constructs indicated that failure of our earlier subclone to be transcribed was due to the lack of an essential downstream promoter element. To determine whether this element is the B block-like sequence, five different truncated $3^{\prime}$ ends were tested in combination with the functional $-1205^{\prime}$ end (Fig. 1): $+387,+312$, and +246 all contain the putative B block promoter element, although +246 has only an additional $3 \mathrm{bp}$ downstream of it; +235 replaces all but the first $2 \mathrm{bp}$ of the B block with vector DNA (Fig. 2 c) and +145 has only 30 bp of yeast DNA downstream of SNR6. In vitro, all $3^{\prime}$ deletions containing the B block have approximately equal activity (Fig. 3, lanes 6, 10-12), but those lacking most or all of the B block are completely inactive (lanes 8 and 9).

To confirm that the inactivity of the +145 and +235 deletions is due to lack of a functional B block and not a result of bringing inhibitory sequences into the prox- imity of the U6 gene, a 2-bp deletion was made in the B block of the $-120 /+629$ construct, removing base pairs +238 and +239 . Base pair +238 corresponds to the $\mathrm{C}$ residue at position 5 of the $B$ block consensus; mutations at this position are the most detrimental to TFIIIC binding (Baker et al. 1986) and promoter function (Allison et al. 1983; Newman et al. 1983; Fabrizio et al. 1987) yet identified in yeast tRNA genes. The SNR6 B block is palindromic, with the axis of symmetry between positions +238 and +239 . Thus, the +239 deletion removes the corresponding position $5 \mathrm{C}$ residue from the reverse orientation, precluding any possible bidirectional activity of the downstream B block. The $+238 /+239$ deletion construct is completely inactive in vitro (Fig. 3, lane 13), verifying that it is the B block itself that is essential for yeast U6 gene transcription. (Template mixing experiments showed that this DNA preparation did not contain inhibitors of U6 gene transcription).

In addition to the requirement for $5^{\prime}$-flanking sequences and the downstream B block, intragenic sequences were also found to affect the level of yeast U6 synthesis. In vitro transcription of a mutant lacking 22 bp of $3^{\prime}$-coding sequence $(\Delta+87 /+108$; kindly provided by $\mathrm{R}$. Bordonné) yielded at least fourfold more RNA than was obtained from the same amount of wild-type template (Fig. 3, cf. lanes 14 and 15). It is not clear whether this is due to the decreased distance between the B block and the site of initiation (see Discussion) or to the removal of inhibitory sequences. With respect to the latter possibility it may be significant that within this deletion lies an 8-bp direct repeat of sequences present in the upstream PSE-like region (cf. positions $-55 /-48$ with $+102 /+109)$.

The deletion analysis also provides clues to the identity of the four additional discrete transcripts produced by the full-length SNR6 clone. Their approximate lengths are 235, 260, 275, and 295 nucleotides (Fig. 3a). These transcripts are produced by all the 5 -deletion constructs, including $+6 /+629$ and, therefore, do not require sequences upstream of $S N R 6$ for their synthesis. Indeed, linearization of the template at the BclI site in the middle of the U6 gene abolishes U6 snRNA synthesis but does not affect accumulation of the 235-295 nucleotide products (data not shown). However, the $+87 /+108$ deletion construct does not generate the longest transcript (Fig. 3a, lane 14), whose promoter or coding sequence must therefore overlap with the U6 gene. None of the transcripts is produced by the $+238 / 239$ deletion, so their synthesis is also B-block dependent, but because the B block is palindromic, one can not infer from this the orientation of the transcripts. The 3 ' deletions that maintain the B block $(+246,+312$, +387) do not produce the 235-295 nucleotide transcripts, but instead generate longer transcripts whose lengths correlate with the extent of the deletion (visible in Fig. 4, indicated by arrows). From these data, we conclude that the four transcripts most likely initiate immediately downstream of the U6 gene (approximately at positions $+125,+145,+160$, and +185$)$ and terminate 


\begin{tabular}{|c|c|c|c|c|c|}
\hline $\begin{array}{lr}\text { a } & -531 \\
\text { GATCGATAA }\end{array}$ & $\begin{array}{r}-521 \\
\text { TCTCCATAA }\end{array}$ & $\begin{array}{r}-511 \\
\text { TAGTTCTGTT }\end{array}$ & $\begin{array}{r}-501 \\
\text { ATTTATAATC }\end{array}$ & $\begin{array}{r}-491 \\
\text { TCCAGCACTA }\end{array}$ & $\begin{array}{r}-481 \\
\text { ATAAATGCTA }\end{array}$ \\
\hline $\begin{array}{r}-471 \\
\text { CGTATATT }\end{array}$ & $\begin{array}{r}-461 \\
\text { TGTACACAAT }\end{array}$ & $\begin{array}{r}-451 \\
\text { ATAATTTCAG }\end{array}$ & $\begin{array}{r}-441 \\
\text { AATTTATATT }\end{array}$ & $\begin{array}{r}-431 \\
\text { GCTACCATGA }\end{array}$ & $\begin{array}{r}-421 \\
\text { CTGTCTGAGA } \\
\text { solo } \delta>\end{array}$ \\
\hline $\begin{array}{r}-411 \\
I G G G G G A A\end{array}$ & $\begin{array}{r}-401 \\
\text { AACTIGATA }\end{array}$ & $\begin{array}{r}-391 \\
\text { ITGTTGGGA }\end{array}$ & $\begin{array}{r}-381 \\
\text { ITCCATTGIT }\end{array}$ & $\begin{array}{r}-371 \\
\text { TAAACGCA }\end{array}$ & $\begin{array}{r}-361 \\
\text { ATAATATTAG }\end{array}$ \\
\hline $\begin{array}{r}-351 \\
\text { TAGAA }\end{array}$ & $\begin{array}{r}-341 \\
\text { ITACTAAAT }\end{array}$ & $\begin{array}{r}-331 \\
\text { ITCTCTCCG }\end{array}$ & $\begin{array}{r}-321 \\
\text { GGATATAGG }\end{array}$ & $\begin{array}{r}-311 \\
\text { ATGCTCACA }\end{array}$ & $\begin{array}{r}-301 \\
\operatorname{ATCGA}\end{array}$ \\
\hline $\begin{array}{r}-291 \\
\text { TTATTICTA }\end{array}$ & $\begin{array}{r}-281 \\
\text { CATAATAGTA } \\
\end{array}$ & $\begin{array}{r}\delta \mathrm{tx} . \\
-271 \\
\text { TTGAGATTAI }\end{array}$ & $\begin{array}{r}-261 \\
\text { TCCTCTITTA }\end{array}$ & $\begin{array}{r}-251 \\
\text { GTTTTATATA }\end{array}$ & $\begin{array}{r}-241 \\
\text { ATTATC }\end{array}$ \\
\hline $\begin{array}{l}-231 \\
\text { CATT }\end{array}$ & $\begin{array}{l}-221 \\
\text { CCTTT }\end{array}$ & -211 & $\begin{array}{r}-201 \\
-201\end{array}$ & $\begin{array}{c}\delta \text { TATA box } \\
-191\end{array}$ & (1) \\
\hline $\begin{array}{r}-171 \\
\text { ATGTCA }\end{array}$ & $\begin{array}{r}-161 \\
\text { TCTTCCIGGA } \\
\end{array}$ & $\begin{array}{r}-151 \\
\text { TGTGA }\end{array}$ & $\begin{array}{r}\text { UAS } \\
-141 \\
\text { TACTATACCA }\end{array}$ & $\begin{array}{r}-131 \\
\text { ATGAA }\end{array}$ & $\begin{array}{r}-121 \\
\text { CTGAA }\end{array}$ \\
\hline $\begin{array}{r}-111 \\
\text { GATAC }\end{array}$ & $\begin{array}{r}-101 \\
\text { ITTAGAGTTT }\end{array}$ & $\begin{array}{r}-91 \\
\text { CATTGCAACA } \\
<\text { <solo } \delta\end{array}$ & $\begin{array}{r}-81 \\
\text { GTTTCAACAC }\end{array}$ & $\begin{array}{r}-71 \\
\text { AGCCTGGCAT }\end{array}$ & $\begin{array}{r}-61 \\
\text { GTGGT }\end{array}$ \\
\hline $\begin{array}{r}-51 \\
\text { AAAGTATTT }\end{array}$ & $\begin{array}{r}-41 \\
\text { GTCCACTAT }\end{array}$ & $\begin{array}{r}-31 \\
\text { TTTCGGCTAC }\end{array}$ & $\begin{array}{r}-21 \\
\text { TATAAATAAA }\end{array}$ & $\begin{array}{r}-11 \\
\text { TGTTTTTTTC }\end{array}$ & GCAACTATGT \\
\hline $\begin{array}{r}\text { PSE-like sequer } \\
10 \\
\text { STCGCGAAG }\end{array}$ & $\begin{array}{r}20 \\
T C G\end{array}$ & $\begin{array}{r}\text { TA } \\
30 \\
\text { TGGACATTTG } \\
\end{array}$ & $\begin{array}{r}4 \text { TA-like sequence } \\
40\end{array}$ & 50 & 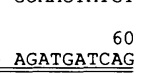 \\
\hline AAGTTCCCCT & $\begin{array}{r}80 \\
\text { GCATAAGGAT } \\
\end{array}$ & $\begin{array}{r}90 \\
\text { GTTTT } \\
\end{array}$ & $\begin{array}{r}100 \\
\text { ACAAAGAGAT }\end{array}$ & $\begin{array}{r}110 \\
\text { ITTCGTT } \\
\end{array}$ & TTTA' \\
\hline $\begin{array}{r}130 \\
\text { ATCGAGTGA }\end{array}$ & $\begin{array}{r}140 \\
\text { CGTGA }\end{array}$ & $\begin{array}{r}150 \\
\text { CATT }\end{array}$ & $\begin{array}{r}160 \\
\operatorname{ATACC}\end{array}$ & $\begin{array}{r}170 \\
A C A G\end{array}$ & ATCT \\
\hline $\begin{array}{r}190 \\
\text { TTATCTTCCT }\end{array}$ & $\begin{array}{r}200 \\
\text { GTATGATATA }\end{array}$ & $\begin{array}{r}210 \\
\text { CTAAC }\end{array}$ & $\begin{array}{r}220 \\
\text { ATCTCGAATA }\end{array}$ & $\begin{array}{r}230 \\
\text { TTGTC }\end{array}$ & TCGC \\
\hline $\begin{array}{r}250 \\
\text { ACCTAAGCCT }\end{array}$ & $\begin{array}{r}260 \\
\text { TCGG }\end{array}$ & $\begin{array}{r}270 \\
\text { ATAG }\end{array}$ & $\begin{array}{r}280 \\
\text { CGCGT }\end{array}$ & & \\
\hline $\begin{array}{r}310 \\
\text { ATGCTATTA }\end{array}$ & $\begin{array}{r}320 \\
\text { ATGT }\end{array}$ & $\begin{array}{r}330 \\
\text { ATGAA }\end{array}$ & & & \\
\hline $\begin{array}{r}370 \\
\text { CGATCATACT }\end{array}$ & CTGAA & САTTTAAATT & ATATATGTCA & AACAGAAGAG & 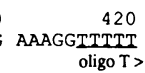 \\
\hline $\begin{array}{r}43 \\
\text { SAAG }\end{array}$ & TT & $\begin{array}{r}450 \\
\text { AATCAATCAT }\end{array}$ & QATAT & $\begin{array}{r}470 \\
\text { ITCGTCC }\end{array}$ & \\
\hline $\begin{array}{r}490 \\
\text { TTCGGCTTTT }\end{array}$ & ACAGC & $\begin{array}{r}510 \\
\text { GAATGATTCT }\end{array}$ & $\begin{array}{r}520 \\
\text { TCCATTATTT }\end{array}$ & $\begin{array}{r}530 \\
\text { GTACCTAGCT }\end{array}$ & CATGG \\
\hline & GTAG? & AACCATGAAC & $\begin{array}{r}580 \\
\text { TCAAA }\end{array}$ & $\begin{array}{r}590 \\
\text { ACTTTCAAAT }\end{array}$ & $\begin{array}{r}60 \\
\text { TGGTGCAAT }\end{array}$ \\
\hline 6 & & & & & \\
\hline
\end{tabular}

CAAGACCCTC CCTTTACATT TGGAGTCGTT transcription (Liao et al. 1987) and the Ty RNA polyadenylation site (Elder et al. 1983) are indicated. (c) Sequence identity of SNR6 positions +234 to +244 with the pol III B block promoter element consensus (Geiduschek and Tocchini-Valentini 1988). Asterisks indicate bases invariant in all eukaryotic tRNA genes. Match of two SNR6 deletion mutants (see text) with the consensus is also shown.

in the stretch of seven $T$ residues at positions +416 to +422 (Fig. 2a). In the $3^{\prime}$-deletion constructs containing the $\mathrm{B}$ block but lacking the oligo $\mathrm{T}$ stretch, the transcripts are expected to continue into vector sequence until encountering an oligo $\mathrm{T}$ stretch there. The location of such oligo $\mathrm{T}$ stretches in the vector is consistent with the approximate length of the observed transcripts. The $+87 /+108$ deletion apparently destroys upstream sequences required for synthesis of the longest transcript. Whether these transcripts, which have not yet been detected in vivo, represent functional RNAs is unknown.

\section{Competition of SNR6 deletion constructs with 5S rDNA}

The identification of a conventional pol III promoter element in a U6 snRNA gene is unprecedented and indicates that initiation of transcription of the yeast U6 gene is likely to involve general pol III factors. That vertebrate U6 genes also use general pol III factors was suggested by competition experiments in which the U6 gene was found to compete with 5S rDNA for a limiting transcription factor in vitro (Reddy et al. 1987) and in

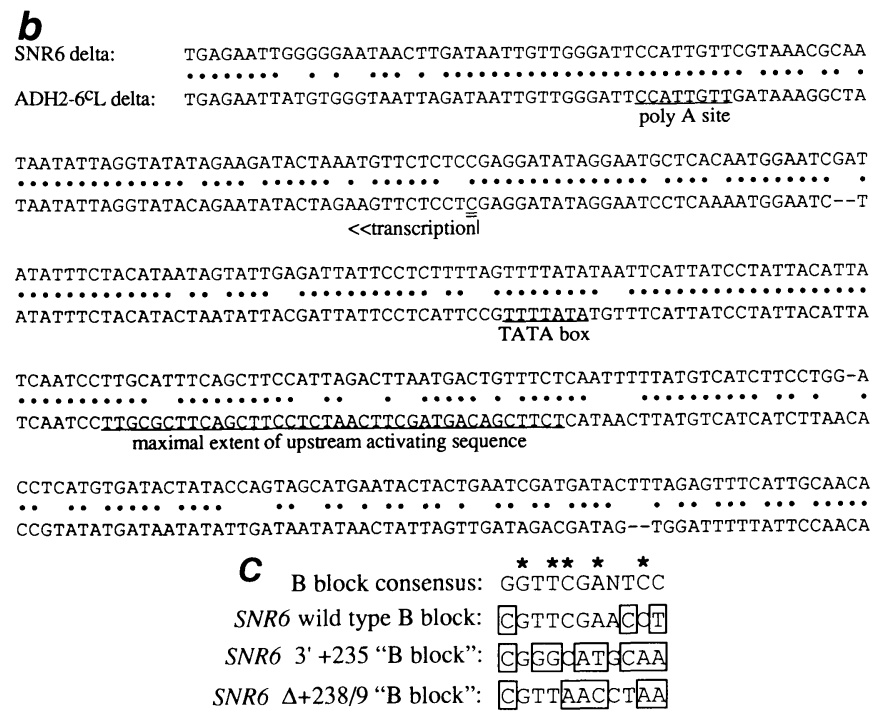

Figure 2. Sequence of DNA encompassing the $S$. cerevisiae U6 gene. (a) Numbering is relative to the first base pair of the U6 snRNA coding sequence, indicated by double underlining. Base pairs -539 to -536 represent the Sau3AI site at the junction of yeast and vector sequence in the original genomic clone; sequences upstream of this in plasmid pEP6 (Brow and Guthrie 1988) derive from pBR322. Because of a numbering (not sequencing) error, the +630 end shown correctly here is referred to as +629 in the rest of the text. No other position assignments are affected by this error. The positions of a solo delta element (and its associated promoter elements) and several potential U6 gene transcriptional control elements (see text) are indicated by underlining. $(b)$ Sequence identity of SNR6 positions -425 to -91 with the Ty retrotransposon delta element $A D H 2-6^{c} L$ (Williamson 1983). Delta sequences that promote Ty vivo (Carbon et al. 1987). Because transcription of $5 \mathrm{~S}$ rRNA genes requires TFIIIB and TFIIIC (as well as the 5S-specific factor TFIIIA), this suggests that vertebrate U6 genes use at least one of these common pol III factors. However, there is no information concerning the binding site on the U6 gene of the pol III factor titrated out by U6 DNA.

We found that the yeast U6 gene can compete with either a tRNA gene or a 5S rRNA gene in the cell-free transcription system (unpubl.). If TFIIIC is the factor sequestered by the yeast U6 gene, or if TFIIIC binding is required for sequestration of another factor (e.g., TFIIIB), the competitive strength of a given SNR6 allele is expected to be related to its ability to bind TFIIIC. We therefore examined the role of the downstream B block in yeast U6 gene competition for limiting transcription factor. The results of an experiment with 5S rDNA as competitor are shown in Figure 4. In the presence of 75 fmole of the $-120 /+629$ SNR6 construct, transcription of 20 fmole of 5S rRNA gene in $1.5 \mu$ of whole-cell extract is reduced to about $30 \%$ of control levels. However, the $-120 /+235$ construct, which lacks most of the B 


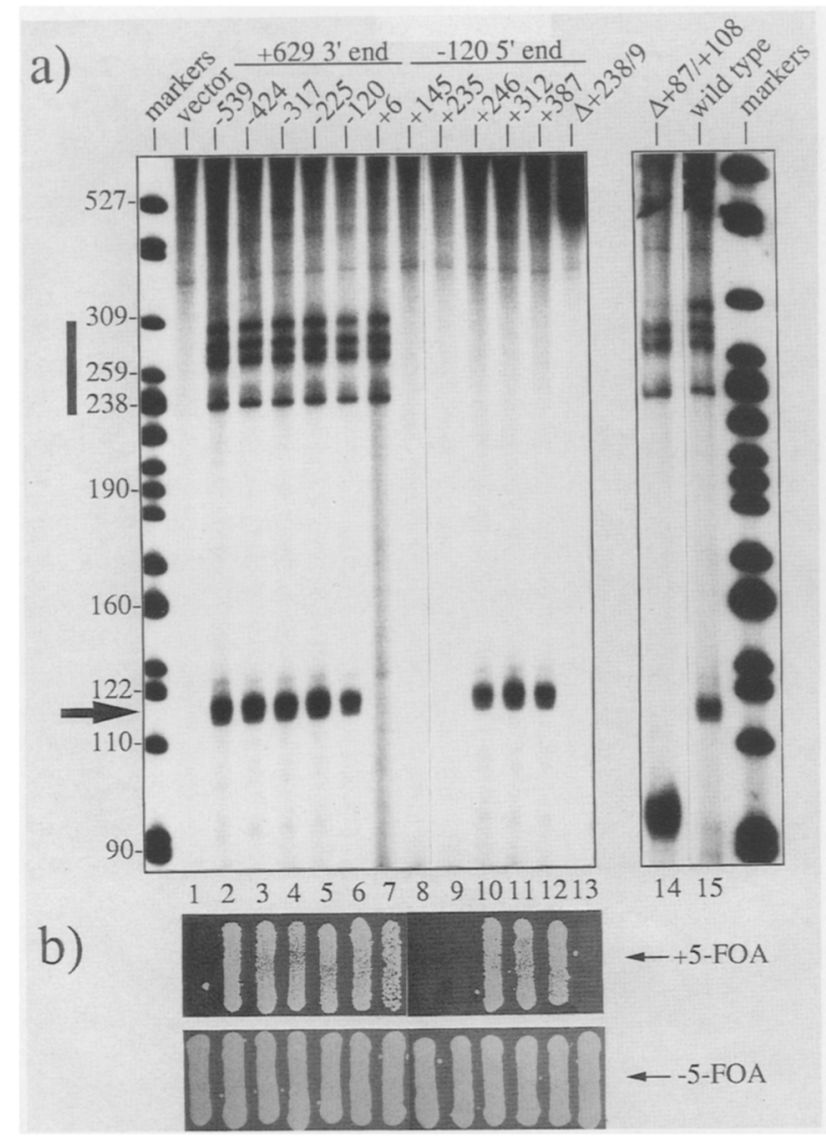

Figure 3. Expression of $S N R 6$ deletion constructs in vitro and in vivo. (a) Lanes 1-13: pUC118 DNA containing no insert (vector) or the indicated SNR6 fragment (see Fig. 1) in the multiple cloning site was incubated in whole-cell extract with NTPs and $\left[{ }^{32} \mathrm{P}\right]$ GTP as described in Methods, and transcripts resolved on a $6 \%$ polyacrylamide, $7 \mathrm{M}$ urea gel. The arrow shows the position of U6 snRNA and the bar, the position of the unidentified high molecular weight transcripts (see text). (Lanes 14 and 15) A similar transcription reaction in which the template was pBluescript DNA containing the 1.4-kb EcoRVHpaI fragment of pEP6 (i.e., SNR6 -539/+629 with some vector DNA/ with or without the indicated intragenic deletion. Markers are a HpaII digest of pBR325. (b) S. cerevisiae strain DAB $017 \quad[\alpha$ trp1 leu2 ura3 his4 can1 snr6 :: LEU2 YCpEP6(URA3/SNR6)] was transformed with pSE358 (CEN4 ARS1 TRP1) alone (vector) or with the indicated SNR6 fragment inserted in the multiple cloning site. After growth to saturation in synthetic medium lacking leucine, tryptophan, and uracil, transformants were patched on synthetic medium lacking leucine and tryptophan, with or without $0.75 \mathrm{mg} / \mathrm{ml}$ 5-FOA. Growth in the presence of 5-FOA (Boeke et al. 1987) requires the loss of YCpEP6, and therefore indicates that the SNR6 deletion construct borne on pSE358 can functionally replace the full-length SNR6 allele on YCpEP6.

block, competes no better than vector DNA. The construct containing the entire B block and $3 \mathrm{bp}$ of downstream sequence $(-120 /+246)$ is not a strong competitor, reducing $5 \mathrm{~S}$ rDNA transcription only by about a quarter, to $72 \%$ of control. Thus, even though this deletion construct is transcribed in vitro with approximately the same efficiency as the full-length clone, the absence of sequences downstream of the B block must impair its ability to bind a factor limiting for 5S rDNA transcription. The additional sequences important for binding must be $<66$ bp downstream of the B block, as constructs containing the +312 and +387 end points exhibit full competitive strength. Sequences within the B block are essential for competition, as the $\Delta+238 / 9$ internal deletion construct competes no better than vector DNA (data not shown).

The qualitative correlation between transcriptional activity and competitive strength of the deletion constructs strongly suggests that a single factor, which binds the downstream B block, is required for both the transcription of the U6 gene and its competition with

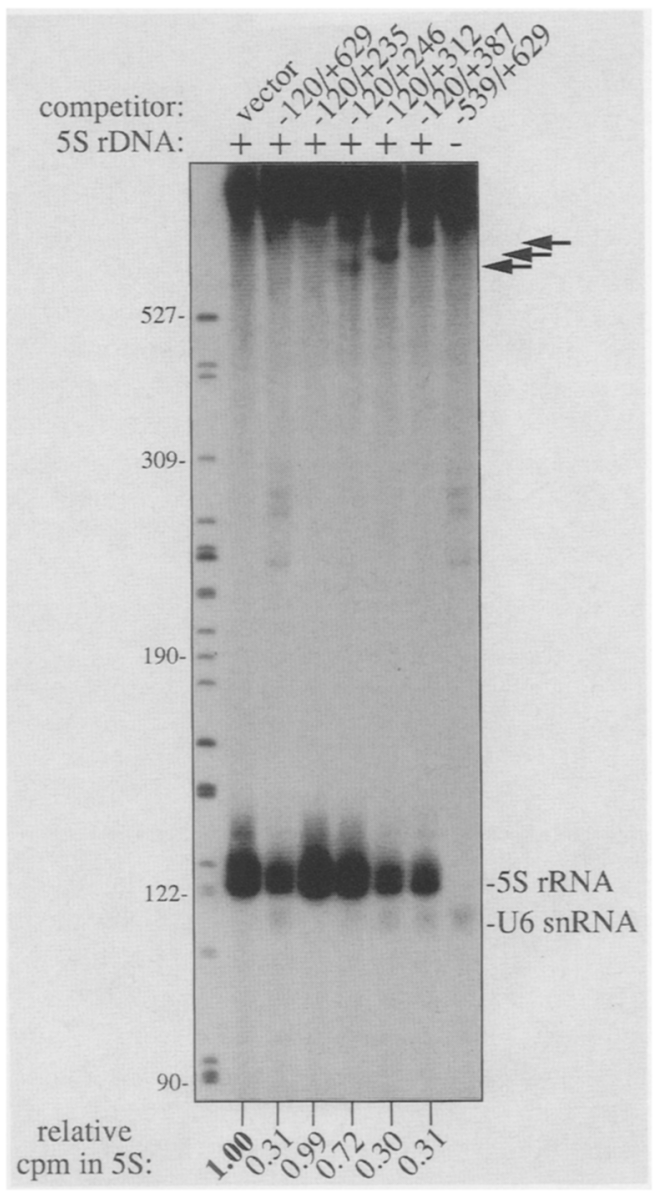

Figure 4. Competition of SNR6 constructs with $5 S$ rDNA. Mixtures of $200 \mathrm{ng}(\sim 75 \mathrm{fmole})$ of vector DNA or the indicated SNR6 deletion construct and $45 \mathrm{ng}$ ( $20 \mathrm{fmole}$ ) of pB-1 (5S rDNA) were incubated with $1.5 \mu \mathrm{l}$ of whole-cell extract for $10 \mathrm{~min}$. NTPs were then added and transcription allowed to proceed for 45 min. Products were resolved on a denaturing gel and bands corresponding to $5 \mathrm{~S}$ rRNA were excised. Yield of transcript was quantitated by liquid scintillation. The yield relative to control $(1386 \mathrm{cpm})$ is indicated below each lane. The rightmost lane shows transcription of full-length SNR6 clone in the absence of $5 S$ rDNA. The arrows indicate the position of presumptive elongated forms of the 235-295 nt transcripts, resulting from deletion of the oligo $\mathrm{T}$ stretch (see text) and visible here because of the shorter exposure time. 
the 5S rRNA gene. The quantitative difference in transcription activity and competitive strength of the $-120 /+246$ construct could be explained if the B-blockbinding factor is not limiting for U6 gene transcription, so its reduced affinity for the $-120 /+246$ template, indicated by the competition results, does not significantly alter the yield of U6 transcript. Of course, the most likely candidate for the B-block-binding factor is TFIIIC. To our knowledge, the contribution of sequences downstream of the B block to the strength of TFIIIC binding has not yet been assessed. However, Camier et al. (1985) report that dimethyl sulfate footprinting of highly purified TFIIIC on a yeast tRNA gene reveals contacts of the factor with nucleotides 8 and 9 bp downstream of the B block; disruption of similar contacts may be responsible for the decreased competitive strength of the $-120 /+246$ construct.

The U6 gene is a surprisingly strong competitor of $5 \mathrm{~S}$ rDNA transcription in view of its relatively low transcriptional activity (see Fig. 4), which is therefore unlikely to be due to inefficient binding of the factor limiting for 5S rRNA synthesis. Rather, binding of other components of the initiation complex, or perhaps events after initiation (i.e., elongation, termination, or reinitiation) may limit U6 snRNA synthesis in vitro. It is also notable that the observed competition is nonreciprocal. This could be a consequence of the requirement of $5 \mathrm{~S}$ rDNA to bind TFIIIA before binding the common factors, TFIIIC and TFIIIB, thus allowing the U6 gene time to sequester these factors. Alternatively, the amount of $5 \mathrm{~S}$ rDNA present might not be sufficient to make the common factors limiting for U6 snRNA synthesis. More extensive competition analyses, including a variation of the order of template addition, will be required to discriminate between these possibilities.

\section{In vivo expression of SNR6 deletion constructs}

Previous studies in mammalian systems have shown that sequences required for maximal transcription of the U6 gene in vitro and in vivo differ markedly, with the latter extending much farther upstream in the $5^{\prime}$ flanking DNA. It was therefore important to determine the activity of our SNR6 deletion constructs in yeast cells. In vivo expression was assayed by a plasmid shuffle protocol (Boeke et al. 1987) in which a full-length SNR6 allele on a URA3 plasmid was replaced by each of the various deletion constructs, carried on a TRP1 plasmid. This was done in a haploid strain with a targeted disruption of the single-copy, essential SNR6 locus. We have shown previously that this strain is completely dependent on the $S N R 6 / U R A 3$ plasmid for growth, evidenced by its inability to survive plating on medium containing the drug 5-fluoroorotic acid (5-FOA), which selects for the small fraction of cells that have spontaneously lost the SNR6/URA3 plasmid (Brow and Guthrie 1988). However, this strain does not exhibit 5-FOA lethality if it contains an additional functional copy of the U6 gene, unlinked to the URA3 gene. Expression of U6 snRNA from 5'- and 3'-deleted SNR6 al- leles was therefore tested by introduction into this strain on a TRP1 plasmid and the subsequent plating of the cells on medium containing 5-FOA. Growth is indicative of a functional allele of SNR6 on the TRP1 plasmid.

With one striking exception, the in vivo results closely parallel the in vitro data (Fig. 1). Plasmids containing the deletion alleles with end points from -539 to -120 all rescue the strain with a chromosomal SNR6 disruption after plating onto 5-FOA-containing medium, indicating that these constructs are expressed (Fig. 3b, patches 2-6). As also expected, all the 3 ' deletions that are transcribed in vitro, rescue in vivo, and those that are not transcribed, including the 2-bp deletion in the $B$ block, do not rescue (Fig. 3b, patches $8-13$ ). Thus the downstream B block is essential in vivo as well as in vitro.

The exceptional clone is the $+6 /+629$ construct, which produces no U6 snRNA in vitro, but is active in vivo (Fig. 3, patch 7). This is despite the fact that the conserved PSE-like and TATA-like elements have been replaced by vector DNA. When RNA was isolated from strains containing the active deletion constructs, and the amount of U6 snRNA determined by Northern analysis, the only strain with a significantly altered level of SNR6 expression was the one carrying the $+6 /+629$ deletion allele (Fig. 5). It produced half as much U6 snRNA as the strain containing the next most extensive $5^{\prime}$ deletion (cf. lanes 8 and 9). Furthermore, the RNA produced by this construct appeared to be slightly shorter than wild-type yeast U6 snRNA. Primer extension of U6 snRNA synthesized in vivo from the $+6 /+629$ deletion allele confirmed that it is one nucleotide shorter than wild-type U6 and has vector sequence at its $5^{\prime}$ end (Fig. 6a).

How is this truncated gene expressed in the absence of the conserved upstream elements? An alignment of wild-type and $+6 /+629$ SNR6 upstream sequences reveals a fortuitous 5 of 8 match between the vector DNA in the $+6 /+629$ construct and the SNR6 TATA-like sequence, with identical spacing from the transcription initiation site mapped by primer extension (Fig. 6b). Furthermore, immediately flanking the coding sequence is another 5 of 8 match. In the position of the 3'-PSE-like box only a 1 of 11 match is found, although a 7 of 11 match is present in the $+6 /+629$ construct 5 bp closer to the TATA-like element, as shown in Figure 6b. Thus, although we cannot yet rule out dispensability of these upstream conserved elements, expression of the $+6 /+629$ construct in vivo is most likely due to fortuitous sequence identity between the vector and SNR6 5 '-flanking DNA.

The inability of the $+6 /+629$ construct to be transcribed in vitro indicates clearly that the U6 promoter has been damaged significantly. Why then is in vivo expression of U6 snRNA from this template down at most only twofold? One possibility is that an upstream binding factor is present in limiting concentration in the cell-free system, but not in vivo. This would render the cell-free system more sensitive to mutations 


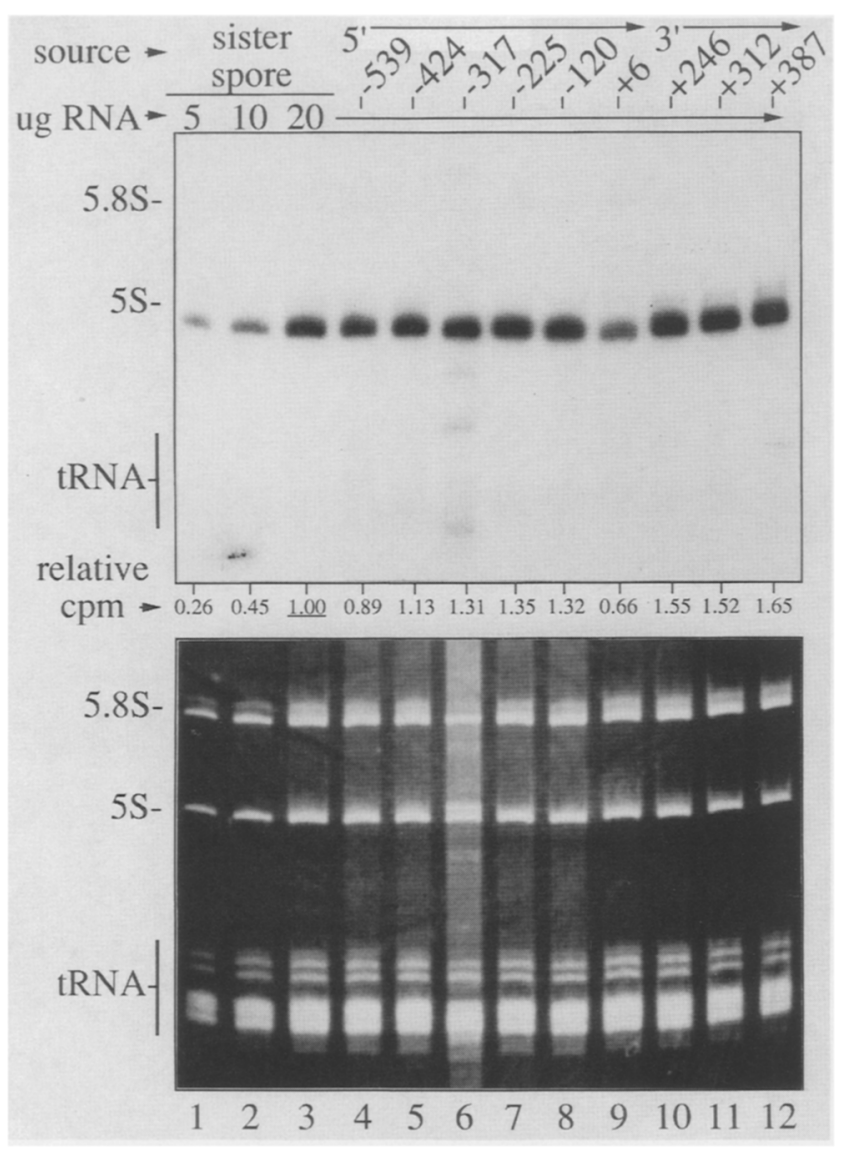

Figure 5. Northern analysis of U6 expression from SNR6 deletion constructs. Twenty micrograms of total RNA from $S$. cerevisiae strain DAB017 transformed with the indicated SNR6 deletion constructs and cured of the wild-type allele by growth in the presence of 5-FOA (see legend of Fig. 3B) or the indicated amount of RNA from a sister spore (DAB014) with a wild-type chromosomal SNR6 allele and carrying no plasmid, was electrophoresed on a denaturing gel, transfered to nylon membrane, and probed with a $32 \mathrm{P}$-labeled oligonucleotide (6B) complementary to residues 67-82 of $S$. cerevisiae U6 snRNA. (Top) Autoradiograph of the Northern blot. The amount of hybridized probe in each lane was quantitated by excision of the U6 snRNA band from the membrane and measurement of radioactivity by liquid scintillation; counts per minute relative to 20 $\mu \mathrm{g}$ of sister spore RNA $(620 \mathrm{cpm})$ are given below each lane. The sister spore RNA titration confirms the linearity of the assay. (Bottom) Ethidium bromide stain of the denaturing gel before transfer to confirm that approximately equal amounts of intact RNA are present in lanes 3-12.

that decrease the affinity of upstream promoter elements for the putative factor. Alternatively, there may exist in the cell a compensatory regulatory mechanism to counteract the decreased U6 snRNA synthesis resulting from replacement of the wild-type SNR6 allele with the $+6 /+629$ construct. At present, however, there is no evidence for such feedback regulation of U6 snRNA synthesis in any organism.

Although we have not yet determined the growth rate or temperature sensitivity of strains producing U6 snRNA from the $+6 /+629$ construct, their viability in- dicates that changes in the 5' end of the RNA due to the presence of vector sequence are not grossly deleterious to function. Figure $6 \mathrm{c}$ compares the proposed structure of the 5 '-terminal stem of $+6 /+629$ U6 snRNA with wild type and the consensus structure for all U6 snRNAs. Although $+6 /+629$ U6 snRNA can form the conserved CG pair and retains the CAY sequence at the base of the stem, it has an adenosine rather than the otherwise universally conserved guanosine residue at the $5^{\prime}$ end of the stem, and lacks pairing at the first two positions in the stem. More extensive phenotypic analysis will be required to determine whether these changes from the consensus structure, or the twofold decrease in U6 snRNA level, have a detectable effect on U6 function.

\section{Discussion}

\section{The S. cerevisiae U6 snRNA gene promoter}

We demonstrated that the $S$. cerevisiae U6 snRNA gene has an essential promoter element positioned 120-130 bp downstream of its 3 ' end. The DNA sequence of this element matches closely that of the consensus pol III B block internal control element, known to be the primary binding site of TFIIIC in tRNA genes. Furthermore, deletion in the U6 downstream element of $2 \mathrm{bp}$ corresponding to residues key to binding of TFIIIC by the tRNA B block destroys U6 promoter function in vitro and in vivo. It is, therefore, very likely that the role of the yeast U6 gene downstream B block is to bind TFIIIC. The results of in vitro transcription competition experiments assessing the effect of SNR6 and its $3^{\prime}$-deletion alleles on 5S rRNA gene transcription (Fig. 4) are consistent with binding of TFIIIC by the downstream B block. Thus, the yeast U6 gene promoter has two unexpected features: 1) It uses a conventional pol III promoter element not seen in vertebrate U6 genes, and 2) this essential promoter element is downstream of the gene, a position unprecedented in any pol III transcription unit.

The B block is the dominant element determining promoter strength in tRNA genes, but tDNA transcription also requires an A block element, which directs initiation at a site about $20 \mathrm{bp}$ upstream of its $5^{\prime}$ border. Binding of the A block by TFIIIC is probably a key step in the placement of TFIIIB upstream of tRNA genes (Kassavetis et al. 1990, and references therein). We therefore looked for a match to the 11-bp A block consensus in SNR6. Beginning at position +21 of the $S$. cerevisiae U6 gene is a sequence that is identical to the A block consensus at 6 of the 9 nondegenerate positions (Fig. 7a). Furthermore, two of the three deviations from the consensus are at sites where mutations have been found to be phenotypically neutral; only the $G \rightarrow T$ transversion at the eighth position (Fig. 7a) is known to be a promoter down mutation (Allison et al. 1983). Therefore, it seems likely that this sequence is acting as an A block promoter element, although further mutational analysis will be required to confirm this.

The downstream location of the yeast U6 gene B block 

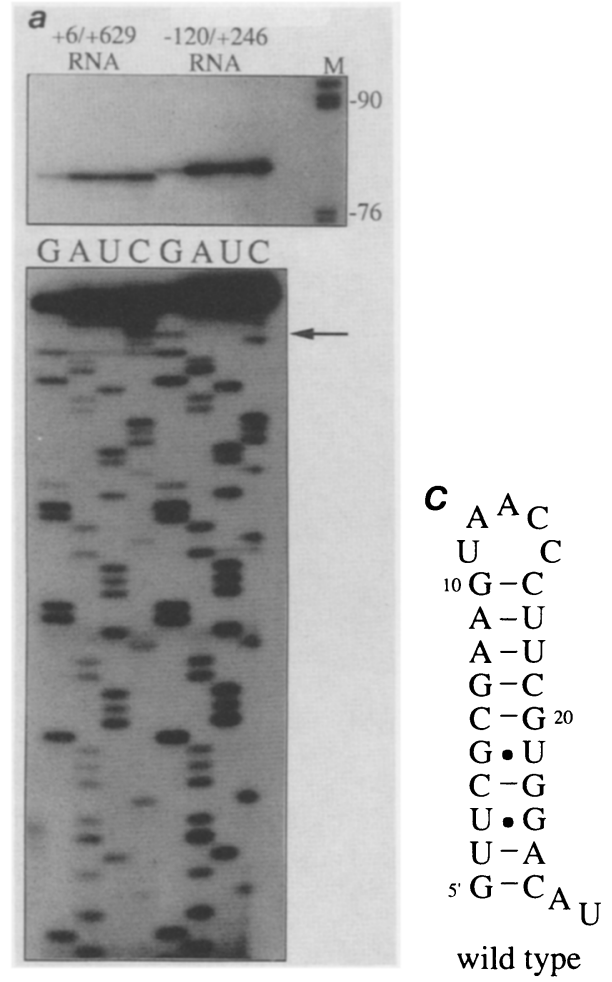
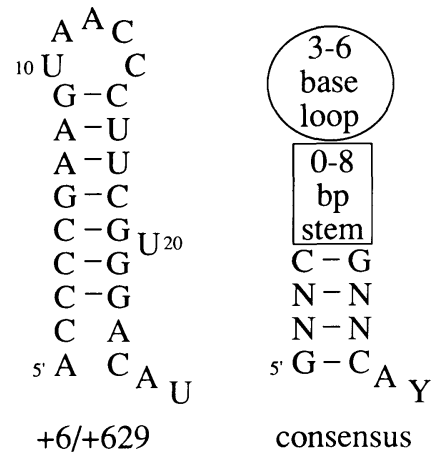

$\boldsymbol{b}$
wild type SNR6:
+6/+629 SNR6:

3'-PSE-like box

TATA-like box
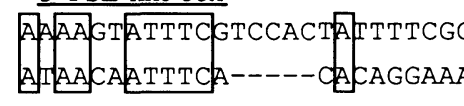

Figure 6. Analysis of the in vivo transcript from the $+6 /+629$ SNR6 construct. (a) Primer extension of total RNA from strains containing the $+6 /+629$ and $-120 /+246$ SNR6 deletion constructs. Total RNA ( $15 \mu \mathrm{g}$ of each) from the preparations used in lanes 9 and 10 of Fig. 5 were subjected to primer extension (in the presence of $2^{\prime}, 3^{\prime}$-dideoxynucleoside triphosphates) with oligonucleotide 6B. Products were displayed on a sequencing gel. The short exposure (top) shows that U6 snRNA from the $+6 /+629$-bearing strain is one nucleotide shorter. The long exposure shows that the $G$ at position 5 in the $-120 /+246$ transcript (arrow) is changed to a $C$ in the $+6 /+629$ transcript, as expected given the substitution of SNR6 coding sequence for vector DNA. (b) Alignment of sequences upstream of the wild-type and $+6 /+629$ alleles of the $S$. cerevisiae SNR6. The wavy arrows indicate the $5^{\prime}$ end of the respective in vivo transcripts, as determined by primer extension. The dashes mark gaps introduced to optimize alignment. $(c)$ Proposed secondary structure of the $+6 /+629$ U6 snRNA 5 '-terminal stem. The $5^{\prime}$-terminus of the transcript of the $+6 /+629$ allele of SNR6 is shown in a secondary structure that most closely conforms to that of wild-type $S$. cerevisiae U6 snRNA (Brow and Guthrie 1988) and the consensus structure for all U6 snRNAs (Roiha et al. 1989). N indicates any nucleotide, Y, a pyrimidine, and a dash base, pairing.

promoter element indicates there is not a fixed spatial relationship between the presumptive TFIIIC binding site and the sites of transcription initiation and termination. An obligatory ordering and/or proximity of these sites might have been expected given the evidence that the La protein, which is implicated in termination of transcription by mammalian pol III (Gottlieb and Steitz 1989 ) and which also may be present in yeast (Brow 1987), appears to be tightly associated with TFIIIC (Gottesfeld et al. 1984; Gottlieb and Steitz 1987). Thus, it has been proposed that, in an active transcription complex, the upstream side of TFIIIC binds TFIIIB and is involved in capturing pol III, whereas the downstream side binds La and facilitates termination (Gottlieb and Steitz 1989). This simple geometry is not possible for the yeast U6 gene, as the initiation and termination sites are both upstream of the B block. The proposed juxtaposition of factors and sites could be achieved, however, by exten- sive looping and folding of the DNA /some degree of which must be required in any case to allow binding of the putative A block by TFIIIC; Fig. 7b). If this in fact occurs, there may be a minimum allowable distance between the termination site and the downstream B block, the extent of which is determined by steric constraints to DNA folding.

The distance between the SNR6 transcription initiation site and its downstream B block (240 bp) is greater than in any other natural pol III transcription unit of which we are aware. However, artificial tRNA gene constructs with similar or even greater spacing (but in which the B block remains intragenic) retain some in vitro promoter activity (Dingermann et al. 1983; Fabrizio et al. 1987). Cannon et al. (1986) studied the effect of progressively increasing the $5^{\prime}$-end to $B$ block spacing by inserting DNA between the A and B block of the adenovirus VARNA1 gene, which has a tRNA-like pol 
a

$$
\begin{array}{rc}
\text { A block consensus: } & \text { TGGCNNAGTGG } \\
\text { SNR6 “A block": } & \text { TGGACATTTGG } \\
\text { "cryptic A block": } & \text { THETACATTTG }
\end{array}
$$
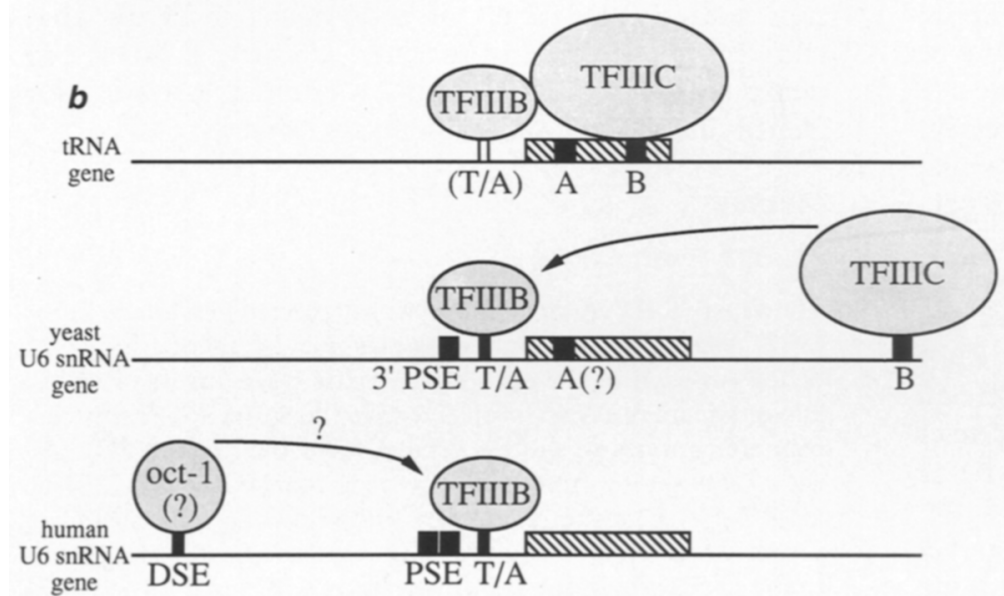

Figure 7. Model for the interaction of pol III transcription factors with yeast and human U6 genes $|a|$ The putative $S$. cerevisiae U6 gene A block sequence is shown below the consensus tRNA gene A block promoter element (Galli et al. 1981). Also shown is a downstream sequence with a 9 of 11 match to the putative yeast U6 A block, which may direct synthesis of the 295 nucleotide downstream transcript (see text). Positions with respect to the U6 snRNA start site are indicated. (b) This highly schematic figure shows a model of transcription complex assembly on a typical tRNA gene and the yeast and human U6 genes. Genes (striped bars) with their associated promoter elements (black bars) are drawn approximately to scale [(A) A block; (B) B block; (T/A) TATA-like sequence; (PSE) proximal sequence element; ( $3^{\prime}$ PSE) portion of human PSE conserved in yeast; (DSE) distal sequence element]. The open bar in the tRNA gene indicates that the TATA-like element is present in some, but not all, tRNA genes. Transcription factors (grey ellipses) are shown in contact with their putative binding sites. Tanaka et al. (1988) have proposed that Oct-1 binds the U2

snRNA gene DSE; the U6 DSE may bind this or another factor. No PSE-binding factor has yet been identified. See Discussion for a detailed description.

III promoter. They found that in vitro transcription efficiency drops off sharply with $5^{\prime}$-end/B block separations greater than about $100 \mathrm{bp}$. Furthermore, with spacings that are greater than $\sim 130 \mathrm{bp}$, alternative initiation sites closer to the B block are used, suggesting the large A-toB block distance promotes the recognition of "cryptic" A blocks. A similar phenomenon may be responsible for the production of the 235-295 nucleotide transcripts from SNR6 clones in the whole-cell extract. For example, the longest of these appears to initiate approximately at position +125 , just downstream of the U6 gene. Nineteen base pairs downstream of this position is a 9 of 11 match to the putative $S N R 6$ A block (Fig. 7a). It should be noted, however, that the effect of the $+87 /+108$ deletion on formation of this transcript (Fig. 3a) indicates that sequences upstream of the presumptive start site are also important for its initiation. The importance of sequences upstream of the U6 gene itself are considered below.

\section{Implications for U6 genes in other organisms}

The SNR6 promoter structure described above is remarkably similar to that of a tRNA gene, suggesting that the $S$. cerevisiae U6 gene is a "missing link" between classical tRNA-like pol III transcription units and the U6 genes of vertebrates, which have exclusively upstream promoters (Fig. $7 \mathrm{~b}$ ). It would be of interest to determine when the shift from tRNA-like to upstream U6 gene promoters occurred in phylogeny. Toward this end we re-examined the published $\mathrm{U} 6$ gene sequences and discovered a 10 of 11 match to the B block consensus in the U6 gene from the fission yeast, Schizosaccharomyces pombe (Tani and Ohshima 1989). Remarkably, this potential B block promoter element is located in the intron (at positions +68 to +78 ), adjacent to and upstream of the UACUAAC sequence at the site of branch formation. The "extragenic" location of the B block in both yeasts may be a reflection of incompatibility of B block sequences with function of the highly conserved U6 snRNA. The $S$. pombe U6 gene also has an A blocklike sequence beginning at position +17 . Within the class Ascomycetes, S. pombe is only distantly related to S. cerevisiae (Sogin et al. 1989). tRNA-like U6 gene promoters may therefore be a general feature of this class, which encompasses most of the yeasts as well as filamentous fungi.

The SNR6 upstream TATA-like element, which is highly conserved in sequence and location $(-29$ to -31$)$ among U6 genes (Fig. 7b), and the A block may collaborate in specification of the U6 snRNA $5^{\prime}$ end. The TATA-like sequence of vertebrate U6 genes has been shown to be the sole determinant specifying their recognition by pol III rather than pol II (Mattaj et al. 1988; Lobo and Hernandez 1989). Kassavetis et al. (1989) and Braun et al. (1989) have shown that the analogous region of tRNA and 5S rRNA genes is bound by TFIIIB in a TFIIIC-dependent fashion. Although many tRNA and 5S rRNA genes do not exhibit a strong upstream sequence dependence, suggesting that TFIIIB can bind in a sequence-independent manner, TATA-like sequences are often present $\sim 30 \mathrm{bp}$ upstream of tRNA and 5S rRNA genes, and, in some cases, are absolutely required for promoter function (Larson et al. 1983; Selker et al. 1986; Garcia et al. 1987). Furthermore, movement of the TATA-like sequence with respect to the coding region of a Neurospora 5S rRNA gene can result in a corresponding shift in the transcriptional start site (Tyler 1987).

A simple explanation of these observations is that 
TFIIIB binds all pol III transcription units $20-30$ bp upstream of the start site, preferentially at a TATA-like sequence, but with little regard to sequence when a strong A block (acting at a distance via TFIIIC) is present. Our data, suggesting an essential role for TFIIIC in SNR6 transcription, support the notion that TFIIIB binds the yeast U6 gene. How might TFIIIB binding be accomplished in vertebrate U6 genes, which lack a B block and so are not expected to bind TFIIIC directly? One can imagine a situation analogous to that which occurs with 5S rRNA genes, which also lack a B block. $5 S$ rDNA binds a gene-specific transcription factor, TFIIIA, via an intragenic promoter element unrelated to the $A$ and $B$ blocks. Binding of TFIIIA is necessary and sufficient for association of TFIIIC with the 5S rRNA gene, which in turn is necessary for the upstream binding of TFIIIB (Braun et al. 1989, and references therein). Thus, TFIIIA effectively replaces the B block sequence, acting as an adaptor between 5S rDNA intragenic sequences and TFIIIC. It is plausible that as yet unidentified proteins that bind sequence elements upstream of vertebrate U6 snRNA genes (e.g., the PSE; Fig. $7 \mathrm{~b})$ perform the same function. Alternatively, U6 genespecific upstream binding proteins could interact directly with TFIIIB, as proposed by Kassavetis et al. (1990).

It is already known that transcription of the mouse U6 gene in vitro requires at least one factor not used by tRNA or 5S rRNA genes (Reddy 1988). This is unlikely to be a DSE-binding protein as the DSE has been shown previously to be dispensible in vitro (Das et al. 1988; Kunkel and Pederson 1988). However, a DSE-binding protein (suggested to be Oct-1 in U2 snRNA genes; Tanaka et al. 1989) may facilitate binding of a U6 PSEbinding factor in vivo (Fig. 7b). Given the far-downstream location of the SNR6 B block, upstream binding proteins may also be required for efficient assembly of the yeast U6 gene transcription complex. In this regard, it will be interesting to determine the effect on yeast U6 synthesis of substitutions in the SNR6 upstream sequences identical to the $3^{\prime}$-half of the human PSE.

Very recently, Moenne et al. (1990) have reported in vitro transcription of our $-120 /+125$ subclone of SNR6 with partially purified TFIIIB and pol III. They find that transcription of this clone, which lacks the downstream B block, does not require TFIIIC. Because we determined that this subclone will not complement the SNR6 disruption and is not transcribed in the whole-cell extract, the TFIIIC independence observed in the purified system is unlikely to be of physiological relevance. However, the work of Moenne et al. provides further evidence in support of the involvement of TFIIIB in U6 gene transcription.

The extragenic location of the yeast U6 gene B block has an important practical ramification: it is expected to greatly facilitate genetic analysis of the TFIIIC-DNA interaction. Previous genetic studies on B block function have been hampered by the fact that mutation of the promoter element also results in changes in the RNA product. The in vivo phenotype therefore could not be used as a measure of promoter function, as it is also influenced by RNA stability and function. In contrast, mutations in the yeast U6 B block do not alter the coding sequence, thus interpretation of their phenotype is much more straightforward, as illustrated by our deletion analysis. Selection of mutations in TFIIIC that allow its recognition of mutated U6 gene B block elements should be possible and is a promising strategy for identifying specific protein-DNA contacts.

\section{Methods}

\section{Plasmid constructions}

The yeast $5 \mathrm{~S}$ rDNA clone (pB-1) was described previously (Brow 1987). Yeast U6 gene-containing plasmids are named according to the location of the ends of the yeast DNA insert (with the end upstream of SNR6 first), and have the suffix " 6 ". Yeast centromere-containing shuttle vectors have the prefix "YC". All constructs derive from pVH6, which consists of the 1357-bp EcoRV-HpaI fragment of pEP6 (Brow and Guthrie 1988) inserted in the HincII site of pUC118, with the EcoRV end closest to the EcoRI site in the polylinker. [pUC118 is pUC18 with 476 bp of M13 DNA (5465-5941) inserted in the NdeI site.] The first $188 \mathrm{bp}$ of the pVH6 insert correspond to the EcoRVBamHI fragment of pBR322, derived from the original genomic clone. The remaining $1169 \mathrm{bp}$ are yeast genomic DNA and are shown in Figure $2 \mathrm{~A}$.

Four of the SNR6 5'-deletion constructs (p-539H6, p-424H6, p-317H6, and p-225H6) were generated by exonuclease III (BRL) digestion of KpnI-BamHI-cut pVH6, followed by S1 nuclease (BRL) digestion, filling in with the Klenow fragment of DNA polymerase I (U.S. Biochemicals), and ligation with T4 DNA ligase (U.S. Biochemicals), essentially as described by Henikoff (1984). All retain the EcoRI site of pUC118. pCH6 $(-120 /$ +629 ) was constructed from p-225H6 by digestion with EcoRI and ClaI, followed by filling in with Klenow and religation. pNH6 $(+6 /+629)$ was constructed by religation of pVH6 digested with SmaI and NruI. For the 3 '-deletion constructs pCR6, pCD6, pCS6, and pCM6, the 770-bp EcoRI-HindIII fragment of pCH6 was digested further with RsaI (+145), DdeI $(+246)$, ScaI $(+312)$, or MseI (+387), respectively, and then ligated with EcoRI-HincII-cut pUC118, filling-in sticky ends with the Klenow fragment of DNA polymerase I as necessary. pCCs $6(-120 /+235)$ was constructed by religation of pCH6 that had been digested with Csp45I (Promega), PstI, and S1 nuclease; pCH6 $\Delta \mathrm{B}(\Delta+238 /+239)$ was constructed by the same procedure, except the PstI digestion was not done. All deletion end points were determined by dideoxynucleotide sequencing with Sequenase (USB). The $+87 /+108$ internal deletion of SNR6 was made by oligo-directed mutagenesis of pRB6.1 [which consists of the EcoRV-HpaI fragment of pEP6 inserted in the EcoRV site of pBluescript|-l, with the upstream sequences closest to the EcoRI site in the polylinker] and was kindly provided by Remy Bordonné. Yeast shuttle vectors containing the various alleles of SNR6 were made by isolating the $E c o$ RI-SphI fragment from each deletion construct and inserting it into EcoRI-SphI-digested pSE358 (related to pUN10, Elledge and Davis 1988).

\section{In vitro transcription}

The $S$. cerevisiae whole-cell extract was prepared according to the procedure of Klekamp and Weil (1982). Unless specified otherwise, the $22.5-\mu l$ transcription reaction contained $40 \mathrm{~mm}$ HEPES ( $\mathrm{pH} 7.9$ ), $100 \mathrm{~mm} \mathrm{NaCl}, 7 \mathrm{mM} \mathrm{MgCl}_{2}, 3 \mathrm{~mm}$ dithio- 
threitol, 200 ng of DNA and $2 \mu 1$ of whole-cell extract. After incubation at $20^{\circ} \mathrm{C}$ for $15 \mathrm{~min}, 2.5 \mu \mathrm{l}$ of NTP mix [0.6 mM each ATP, CTP, and UTP, and $25 \mu \mathrm{M}(8 \mu \mathrm{Ci})\left[\alpha^{-32}\right.$ P]GTP in transcription buffer was added, and incubation continued for 45-60 min. Transcription was terminated and transcripts purified as described previously (Brow 1987).

\section{In vivo expression}

S. cerevisiae strains were transformed by the lithium acetate method (Ito et al. 1983) with DNA prepared by the boiling method (Holmes and Quigley 1981) from $0.3 \mathrm{ml}$ of a saturated culture of Escherichia coli. Total RNA was extracted from cells in the presence of guanidinium thiocyanate as described by Wise et al. (1983) and electrophoresed on a $6 \%$ polyacrylamide, $7 \mathrm{M}$ urea gel. The gel was stained for $30 \mathrm{~min}$ with $0.5 \mu \mathrm{g} / \mathrm{ml}$ ethidium bromide in $20 \mathrm{mM} \mathrm{NaH} \mathrm{PO}_{4}(\mathrm{pH} 6.5)$ and photographed. RNA was transferred to a nylon membrane and the blot was hybridized with $4 \times 10^{6} \mathrm{cpm}$ (Cerenkov) of $5^{\prime}-32 \mathrm{P}$ labeled oligonucleotide 6B (5'-TCATCCTTATGCAGGG-3') in $20 \mathrm{ml}$ as described (Brow and Guthrie 1988) except incubation with probe was for 2 days and exposure was for 6 days without intensifying screen.

\section{Primer extension analysis}

RNA was subjected to oligonucleotide-primed dideoxynucleotide sequencing according to procedure 2 of Geliebter et al. (1986) with the following modifications. Approximately $7 \times 10^{5} \mathrm{cpm}(0.7 \mathrm{pmole})$ of oligo $6 \mathrm{~B}$ (see above) was annealed to total RNA for $30 \mathrm{~min}$ at $45^{\circ} \mathrm{C}$, and reverse transcription (without actinomycin D) was also carried out at $45^{\circ} \mathrm{C}$ for 30 min. The gel $(6 \%$ polyacrylamide, $7 \mathrm{M}$ urea) was exposed to Kodak XAR- 5 film for 5 days without (short), or 8 days with, a Lightning Plus (DuPont) intensifying screen.

\section{Acknowledgments}

We thank Remy Bordonné for providing the SNR6 $\Delta+87 /+108$ construct, and George Kassavetis, Peter Geiduschek, Tom Steinberg, and Dick Burgess for communicating unpublished results. We are grateful to members of the Guthrie lab and Mitch Sogin for discussions, and to Remy Bordonné, Jim Dahlberg, Peter Geiduschek, and Elsebet Lund for comments on the manuscript. This work was supported by grants from the $\mathrm{Na}$ tional Institutes of Health and the National Science Foundation to C.G. D.A.B. was supported by an American Cancer Society Postdoctoral Fellowship.

The publication costs of this article were defrayed in part by payment of page charges. This article must therefore be hereby marked "advertisement" in accordance with 18 USC section 1734 solely to indicate this fact.

\section{Note added in proof}

Sequence data described in this paper have been submitted to the EMBL/GenBank Data Libraries.

\section{References}

Allison, D.S., S.H. Goh, and B.D. Hall. 1983. The promoter sequence of a yeast tRNAtyr gene. Cell 34: 655-664.

Baker, R.E., O. Gabrielsen, and B.D. Hall. 1986. Effects of tRNATyr point mutations on the binding of yeast RNA polymerase III transcription factor C. J. Biol. Chem. 261: 5275-5282.

Bark, C., P. Weller, J. Zabielski, L. Janson, and U. Pettersson. 1987. A distant enhancer element is required for polymerase III transcription of a U6 RNA gene. Nature 328: 356-359.

Bentley, D., W. Brown, and M. Groudine. 1989. Accurate, TATA box-dependent polymerase III transcription from promoters of the c-myc gene in injected Xenopus oocytes. Genes Dev. 3: 1179-1189.

Boeke, J.D., J. Truehart, G. Natsoulis, and G.R. Fink. 1987. 5Fluoroorotic acid as a selective agent in yeast molecular genetics. Methods Enzymol. 154: 164-175.

Braun, B.R., D.L. Riggs, G.A. Kassavetis, and E.P. Geiduschek. 1989. Multiple states of protein-DNA interaction in the assembly of transcription complexes on Saccharomyces cerevisiae 5S ribosomal RNA genes. Proc. Natl. Acad. Sci. 86: $2530-2534$.

Brow, D.A. 1987. In vitro transcripts of a yeast variant 5S rRNA gene exhibit alterations in $3^{\prime}$-end processing and protein binding. J. Biol. Chem. 262: 13959-13965.

Brow, D.A. and C. Guthrie. 1988. Spliceosomal RNA U6 is remarkably conserved from yeast to mammals. Nature 334: $213-218$.

Cameron, J. R., E.Y. Loh, and R.W. Davis. 1979. Evidence for transposition of dispersed repetitive DNA families in yeast. Cell 16: 739-751.

Camier, S., O. Gabrielsen, R. Baker, and A. Sentenac. 1985. A split site for transcription factor tau on the tRNAglu3 gene. EMBO J. 4: 491-500.

Cannon, R.E., G.-J.Wu, and J.F. Railey. 1986. Functions of and interactions between the $\mathrm{A}$ and $\mathrm{B}$ blocks in adenovirus type 2-specific VARNA1 gene. Proc. Natl. Acad. Sci. 83: 12851289.

Carbon, P., S. Murgo, J. Ebel, A. Krol, G. Tebb, and I. Mattaj. 1987. A common octamer motif binding protein is involved in the transcription of U6 snRNA polymerase III and U2 snRNA by RNA polymerase II. Cell 51: 71-79.

Dahlberg, J.E. and E. Lund. 1988. The genes and transcription of the major small nuclear RNAs. In Structure and function of major and minor small nuclear ribonucleoprotein particles (ed. M. Birnstiel), pp. 38-70. Springer-Verlag, Heidelberg.

Das, G., D. Henning, D. Wright, and R. Reddy. 1988. Upstream regulatory elements are necessary and sufficient for transcription of a U6 RNA gene by RNA polymerase III. EMBO I. 7: 503-512.

Dingermann, T., S. Sharp, J. Schaak, and D. Söll. 1983. Stable transcription complex formation of eukaryotic tRNA genes is dependent on a limited separation of the two intragenic control regions. J. Biol. Chem. 258: 10395-10402.

Elder, R.T., E.Y. Loh, and R.W. Davis. 1983. RNA from the yeast transposable element Tyl has both ends in the direct repeats, a structure similar to retrovirus RNA. Proc. Natl. Acad. Sci. 80: 2432-2436.

Elledge, S.J. and R.W. Davis. 1988. A family of versatile centromeric vectors for use in the sectoring-shuffle mutagenesis assay in Saccharomyces cerevisiae. Gene 70: 303-312.

Fabrizio, P., A. Coppo, P. Fruscoloni, P. Benedetti, G. De Segni, and G.P. Tocchini-Valentini. 1987. Comparative mutational analysis of wild-type and stretched tRNAleu3 gene promoters. Proc. Natl. Acad. Sci. 84: 8763-8767.

Gafner, J., E.M. De Robertis, and P. Philippsen. 1983. Delta sequences in the $5^{\prime}$ non-coding region of yeast tRNA genes. EMBO J. 2: 583-591.

Galli, G., H. Hofstetter, and M.L. Birnstiel. 1981. Two conserved sequence blocks within eukaryotic tRNA genes are major promoter elements. Nature 294: 626-631. 
Garcia, A., A. O'Connell, and S. Sharp. 1987. Formation of an active transcription complex in the Drosophila melanogaster 5S RNA gene is dependent on an upstream region. Mol. Cell. Biol. 7: 2046-2051.

Geiduschek, E. and G. Tocchini-Valentini. 1988. Transcription by RNA polymerase III. Annu. Rev. Biochem. 57: 873-914.

Geliebter, J., R.A. Zeff, R.W. Melvold, and S.G. Nathenson. 1986. Mitotic recombination in germ cells generated two major histocompatibility complex mutant genes shown to be identical by RNA sequence analysis: $\mathrm{K}^{\mathrm{bm} 9}$ and $\mathrm{K}^{\mathrm{bm}}$. Proc. Natl. Acad. Sci. 83: 3371-3375.

Gottesfeld, J.M., D.L. Andrews, and S.O. Hoch. 1984. Association of an RNA polymerase III transcription factor with a ribonucleoprotein complex recognized by autoimmune sera. Nucleic Acids Res. 12: 3185-3200.

Gottlieb, E. and J.A. Steitz. 1987. The mammalian La protein associates with known transcription components. In RNA polymerase and the regulation of transcription (ed. W.S. Reznikoff, R.B. Burgess, J.E. Dahlberg, C.A. Gross, M.T. Record, and M.P. Wickens). pp. 465-468. Elsevier Science Publishing Co., New York.

- 1989. Function of the mammalian La protein: evidence for its action in transcription termination by RNA polymerase III. EMBO J. 8: 851-861.

Guthrie, C. and B. Patterson. 1988. Spliceosomal snRNAs. Annu. Rev. Genet. 22: 387-419.

Henikoff, S. 1984. Unidirectional digestion with exonuclease III creates targeted breakpoints for DNA sequencing. Gene 28: $351-359$.

Holmes, D.S. and M. Quigley. 1981. A rapid boiling method for the preparation of bacterial plasmids. Anal. Biochem. 114: 193.

Ito, H., Y. Fukuda, K. Murata, and A. Kimura. 1983. Transformation of intact yeast cells treated with alkali cations. I. Bacteriol. 153: 163-168.

Kassavetis, G., D. Riggs, R. Negri, L. Nguyen, and E. Geiduschek. 1989. Transcription factor IIIB generates extended DNA interactions in RNA polymerase III transcription complexes of tRNA genes. Mol. Cell. Biol. 9: 2551-2566.

Kassavetis, G. A., B.R. Braun, L.H. Nguyen, and E.P. Geiduschek. 1990. S. cerevisiae TFIIIB is the transcription initiation factor proper of RNA polymerase III, while TFIIIA and TFIIIC are assembly factors. Cell 60: 235-245.

Klekamp, M. and P. Weil. 1982. Specific transcription of homologous class III genes in yeast-soluble cell-free extracts. $I$. Biol. Chem. 257: 8432-8441.

Kunkel, G. and T. Pederson. 1988. Upstream elements required for efficient transcription of a human U6 RNA gene resemble those of U1 and U2 genes even though a different polymerase is used. Genes Dev. 2: 196-204.

Kunkel, G., R. Maser, J. Calvet, and T. Pederson. 1986. U6 small nuclear RNA is transcribed by RNA polymerase III. Proc. Natl. Acad. Sci. 83: 8575-8579.

Larson, D., J. Bradford-Wilcox, L. Young, and K. Sprague. 1983. A short 5' flanking region containing conserved sequences is required for silkworm alanine tRNA gene activity. Proc. Natl. Acad. Sci. 80: 3416-3420.

Liao, X.-B., J.J. Clare, and P.J. Farabaugh. 1987. The upstream activation site of a Ty2 element of yeast is necessary but not sufficient to promote maximal transcription of the element. Proc. Natl. Acad. Sci. 84: 8520-8524.

Lobo, S. and N. Hernandez. 1989. A 7-bp mutation converts a human RNA polymerase II snRNA promoter into an RNA polymerase III promoter. Cell 58: 55-67.

Mattaj, I., N. Dathan, H. Parry, P. Carbon, and A. Krol. 1988. Changing the RNA polymerase specificity of U snRNA gene promoters. Cell 55: 435-442.

Moenne, A., S. Camier, G. Anderson, F. Margottin, J. Beggs, and A. Sentenac. 1990. The U6 gene of Saccharomyces cerevisiae is transcribed by RNA polymerase C (III) in vivo and in vitro. EMBO J. 9: 271-277.

Murphy, S., C. Di Liergro, and M. Melli. 1987. The in vitro transcription of the 7SK RNA gene by RNA polymerase III is dependent only on the presence of an upstream promoter. Cell 51: 81-87.

Newman, A.J., R.C. Ogden, and J. Abelson. 1983. tRNA gene transcription in yeast: effects of specified base substitutions in the intragenic promoter. Cell 35: 117-125.

Piper, P.W., A. Lockheart, and N. Patel. 1984. A minor class of 5S rRNA genes in Saccharomyces cerevisiae X2180-1B, one member of which lies adjacent to a Ty transposable element. Nucleic Acids Res. 12: 4083-4096.

Reddy, R. 1988. Transcription of a U6 small nuclear RNA gene in vitro: transcription of a mouse U6 small nuclear RNA gene in vitro by RNA polymerase III is dependent on transcription factor(s) different from transcription factors IIIA, IIIB, and IIIC. J. Biol. Chem. 263: 15980-15984.

Reddy, R., D. Henning, G. Das, M. Marless, and D. Wright. 1987. The capped U6 small nuclear RNA is transcribed by RNA polymerase III. J. Biol. Chem. 262: 75-81.

Roiha, H., E.O. Shuster, D.A. Brow, and C. Guthrie. 1989. snRNAs from budding yeasts: phylogenetic comparisons reveal extensive size variation. Gene 82: 137-144.

Sawadogo, M. and R.G. Roeder. 1985. Interaction of a gene-specific transcription factor with the adenovirus major late promoter upstream of the TATA box region. Cell 43: 165-175.

Schultz, L.D. and B.D. Hall. 1976. Transcription in yeast: alpha-amanitin sensitivity and other properties which distinguish between RNA polymerases I and III. Proc. Natl. Acad. Sci. 73: 1029-1033.

Selker, E., E. Morzycka-Wroblewska, J. Stevens, and R. Metzenberg. 1986. An upstream signal is required for in vitro transcription of Neurospora 5S RNA genes. Mol. Gen. Genet. 205: 189-192.

Sogin, M.L., U. Edman, and H. Elwood. 1989. In The hierarchy of life (ed. B. Fernholm, K. Bremer, and H. Jörnvall). pp. 133-143. Elsevier Science Publishing Co., New York.

Steinberg, T.H., D.E. Mathews, R.D. Durbin, and R.R. Burgess. 1990. Tagetitoxin: a new inhibitor of eukaryotic transcription by RNA polymerase III. J. Biol. Chem. 265: 499-505.

Tanaka, M., U. Grossniklaus, W. Herr, and N. Hernandez. 1988. Activation of the U2 snRNA promoter by the octamer motif defines a new class of RNA polymerase II enhancer elements. Genes Dev. 2: 1764-1778.

Tani, T. and Y. Ohshima. 1989. The gene for the U6 small nuclear RNA in fission yeast has an intron. Nature 337: 8790.

Tyler, B. 1987. Transcription of Neurospora crassa 5S rRNA genes requires a TATA box and three internal elements. $I$. Mol. Biol. 196: 801-811.

Valenzuela, P., G.L. Hager, F. Weinberg, and W.J. Rutter. 1976. Molecular structure of yeast RNA polymerase III: demonstration of the tripartite transcription system in lower eukaryotes. Proc. Natl. Acad. Sci. 73: 1024-1028.

Williamson, V.M. 1983. Transposable elements in yeast. Int. Rev. Cytol. 83: 1-25.

Wise, J.A., D. Tollervey, D. Maloney, H. Swerdlow, E.J. Dunn, and C. Guthrie. 1983. Yeast contains small nuclear RNAs encoded by single copy genes. Cell 35: 743-751. 


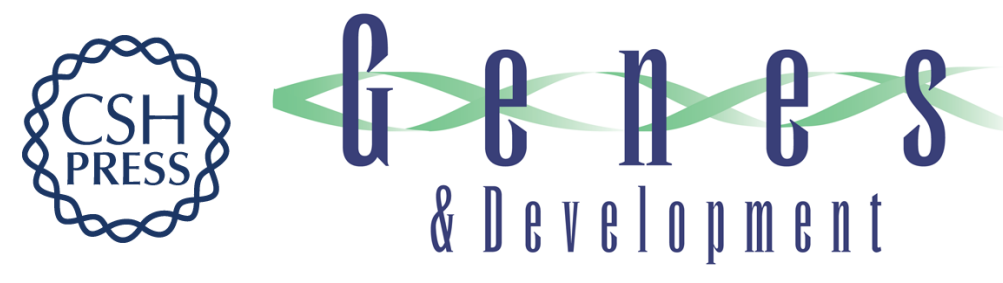

\section{Transcription of a yeast U6 snRNA gene requires a polymerase III promoter element in a novel position.}

D A Brow and C Guthrie

Genes Dev. 1990, 4:

Access the most recent version at doi:10.1101/gad.4.8.1345

\section{License}

Email Alerting

Service

Receive free email alerts when new articles cite this article - sign up in the box at the top right corner of the article or click here.

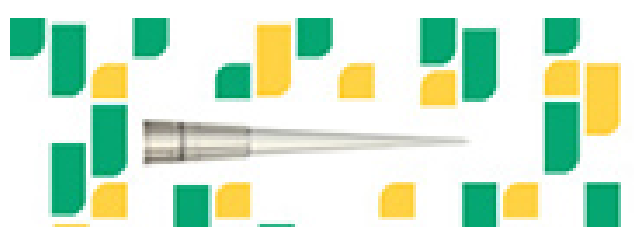

Focused on your science. 